\title{
Poor response to therapy for bullous pemphigoid lesions located on the hemiplegic half of the body
}

\author{
Şirin Yaşar ${ }^{*}$, Dua Cebeci ${ }^{1}$, Sema Aytekin ${ }^{1}$, Fatih Göktay ${ }^{1}$ and Pembegül Güneş ${ }^{2}$ \\ ${ }^{1}$ Department of Dermatology, Haydarpaşa Numune Training and Research Hospital, Turkey \\ ${ }^{2}$ Department of Pathology, Haydarpaşa Numune Training and Research Hospital, Turkey
}

\section{To the editor,}

Bullous pemphigoid (BP) is an autoimmune disease prevalent in elderly patients characterized by the formation of subepidermal blisters or bullae. In BP, histopathological evidence indicates that autoantibodies are directed against two hemidesmosomal proteins, designated BP180 and BP230. Although there are theories of blister formation, the causes of the formation of autoantibodies are not fully understood. BP may be associated with autoimmune diseases, inflammatory dermatoses, malignancies, or neurological disorders. Various neurological diseases, in particular, have been reported in association with BP, including cerebrovascular disease, dementia, multiple sclerosis, epilepsy, Parkinson's disease, Shy Drager syndrome, and amyotrophic lateral sclerosis [1-3].

A 74-year-old female patient presented with a 1.5-month history of itchy and bullous lesions containing serous fluid on different parts of her body. She had a history of diabetes mellitus, hypertension, and goitre. She had Broca's aphasia and complete right hemiplegia following a left-side cerebrovascular accident three years earlier. Dermatological examination showed flaccid bullae with bullae residues of $0.5-5 \mathrm{~cm}$ in diameter and erosions predominately on the trunk, shoulders, arms, and legs. We performed a biopsy, in which subepidermal detachment and eosinophil predominance mixed inflammatory infiltrate were detected (Figure 1e). In a direct immunofluorescence biopsy within perilesional skin, linear IgG and C3 deposition were found to be positive at the dermal-epidermal junction. We could not study indirect immunofluorescence BpAg1 (230 kDa) and BpAg2 (180 kDa) because we did not have the equipment to perform the test/analysis. We diagnosed her condition as BP, and treatment was started with moderate and high potency topical steroids for about two weeks. Unfortunately, she did not respond well. Because of the generalized lesions and risk of secondary infection, we engaged in systemic treatment. We started with $60 \mathrm{mg} /$ day methylprednisolone and $100 \mathrm{mg}$ dapsone once daily. The lesions showed resistance to dapsone treatment and she began to develop anaemia; therefore, the treatment was discontinued after 13 days. The methylprednisolone was then increased to $120 \mathrm{mg} /$ day and $150 \mathrm{mg} /$ day of azathioprine was added. After increasing the systemic steroid doses, most of the lesions on the left side of the body improved; however, there was poor improvement on the right side with hemiplegia, and large blisters and bullae continued to occur (Figures $1 \mathrm{a}, 1 \mathrm{~b}, 1 \mathrm{c}$ and $1 \mathrm{~d})$.

Previous studies and case reports have suggested that neurological disorders, such as dementia, Parkinson's disease, and multiple sclerosis, may be associated with $\mathrm{BP}$ and that the age of BP occurrence can range from 1.5 years to 60 years. Recently, an association between certain neurological conditions and BP in elderly populations has been reported [4,5]. In neurological diseases associated with BP, AG1 is a common antigen that can play a role in $\mathrm{BP}$ pathogenesis, with BpAG1a occurring in neural tissue, BpAG-1b in muscle, and BpAG-1e in the skin. It has been hypothesized that during neurodegenerative and inflammatory processes, released autoantibodies can develop against neuronal BpAG-1a antigens before interacting with epidermal BpAG-1e, thus causing BP. BP often occurs in elderly individuals, and neurological diseases in this age group are also more common. However, this relationship includes some restrictions. In our patient, the development of BP lesions after a cerebrovascular disorder and especially the resistance to treatment on the right hemiplegic side suggest that cross-reactions may play a role in the association of $\mathrm{BP}$ with neurologic disorders. Unfortunately, we could not study BpAG1, BpAG-1 isoforms, and BpAG-2 because of the lack of an adequate technique. Several studies have shown that BpAG1 is a common autoimmune response in neurological disorders and that accompanying BP may play an important role in these two diseases in elderly people. Perhaps, diseases such as dementia and Parkinson's disease cause immunological cross-reactivity: the neurological event would cause destruction of the blood-brain barrier and consequent exposure of the neuronal isoform BP230, triggering the immune system. It has been suggested that circulating autoantibodies against "dyston" in the neurological system may be identical to BpAG1 [6]. Although we did not perform BpAG1 isoform studies, we suggest a relationship between neurological diseases and BpAG1. BpAG1 is thought to be a marker in the neuroimmune response and even in neurodegenerative diseases.

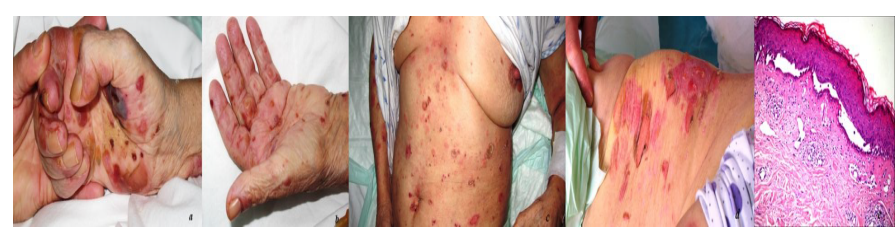

Figures 1. a, b: In the comparison of lesions, more extensive and larger bullae were located on the right hand side than on the left; $\mathrm{c}, \mathrm{d}$ : Extensive and dense open bullae were located on the hemiplegic half of the body; e: Subepidermal acantholysis was consistent with bullous pemphigoid (H\&Ex100).

Correspondence to: Sirin Yasar, Department of Dermatology, Haydarpaşa Numune Training and Research Hospital, Haydarpaşa Numune Eğitim ve Araştırma Hastanesi, Dermatoloji Kliniği, 34746 Üsküdar, İstanbul, Turkey, Tel: 0090 5053991639; Fax: 0090216 3460582; E-mail: drsirin@gmail.com

Received: March 20, 2016; Accepted: April 07, 2016; Published: April 11, 2016 


\section{References}

1. Roujeau JC, Lok C, Bastuji-Garin S, Mhalla S, Enginger V, et al. (1998) High risk of death in elderly patients with extensive bullous pemphigoid. Arch Dermatol 134: 465-469. [Crossref]

2. Okazaki A (1998) Bullous pemphigoid associated with Shy-Drager syndrome. $J$ Dermatol 25: 465-468. [Crossref]

3. Massouye I, Schmied E, Didierjean L, Abba Z, Saurat JH (1989) Bullous pemphigoid and multiple sclerosis: more than a coincidence? J Am Acad Dermatol 21: 63-68. [Crossref]
4. Casasdela Asunción E, Ruano-Ruiz J, Rodríguez-Martín AM, Vélez García-Nieto A, Moreno-Giménez JC (2014) Association between bullous pemphigoid and neurologic diseases: a case-control study. Actas Dermosifiliogr 105: 860-865. [Crossref]

5. Brick KE, Weaver CH, Savica R, Lohse CM, Pittelkow MR, et al. (2014) A populationbased study of the association between bullous pemphigoid and neurologic disorders. $J$ Am Acad Dermatol 71: 1191-1197. [Crossref]

6. Guo L, Degenstein L, Dowling J, Yu QC, Wollmann R, et al. (1995) Gene targeting of BPAG-1: abnormalities in mechanical strength and cell migration in stratified epithelia and neurological degeneration. Cell 81: 233-243. [Crossref]

Copyright: $(\mathbb{C} 2016$ Yaşar S. This is an open-access article distributed under the terms of the Creative Commons Attribution License, which permits unrestricted use, distribution, and reproduction in any medium, provided the original author and source are credited. 